\title{
ATUAÇÃO PROFISSIONAL DOS EGRESSOS DAS LICENCIATURAS DO INSTITUTO FEDERAL GOIANO (2013-2014)
}

http://dx.doi.org/10.5902/2318133841309

\author{
Thiago Oliveira Piloto ${ }^{1}$ \\ Joelma de Moura Ferreira² \\ Luis Antônio Vilalta ${ }^{3}$
}

\section{Resumo}

É objetivo dos institutos federais, entre outros, garantir uma parcela de suas vagas a fim de atender os cursos de licenciatura. Em contrapartida é esperado que os egressos retribuam devolvendo para a sociedade o conhecimento adquirido. Neste artigo apresenta-se os resultados de uma pesquisa que objetivou identificar se os egressos dos cursos de licenciatura do Instituto Federal Goiano - IF Goiano - atuam profissionalmente na área de formação acadêmica específica. A pesquisa foi desenvolvida nos cursos de licenciatura em Matemática, Pedagogia, Ciências Biológicas e Química de diversos campi do IF Goiano, abrangendo as turmas de 2013 e 2014.

Palavras-chave: licenciatura; egressos; Instituto Federal Goiano; desenvolvimento regional.

\section{PROFESSIONAL ACTING OF LICENCIATURES ALUMNI OF THE GOIANO FEDERAL INSTITUTE}

\begin{abstract}
One of the objectives of the federal institutes, among others, is to assure a portion of their vacancies in order to attend licenciature courses. In contrast, it is expected that alumni from those courses are expected to share their knowledge and expertise with the society. From the context presented above, this paper presents the results of a research that aimed to identify if the graduate alumni from licenciature courses of the Goiano Federal Institute - IF Goiano - are currently employed in a area of specific academic training. The research was developed in the licenciature courses in Mathematics, Pedagogy, Biological Sciences and Chemistry of several IF Goiano campuses, based on the classes of 2013 and 2014.

Key-words: licenciature; alumni; Goiano Federal Institute; regional development.
\end{abstract}

\footnotetext{
${ }^{1}$ Instituto Federal Goiano, Brasil. E-mail: thiago.piloto@ifgoiano.edu.br.

2 Centro Educacional Alves Farias, Brasil. E-mail: joelma.ferreira@unialfa.com.br.

${ }^{3}$ Centro Educacional Alves Farias, Brasil. E-mail: vilalta.educacao@gmail.com.

Regae: Rev. Gest. Aval. Educ.

v. 9

n. 18

Pub. contínua 2020

p. 1-17
} 


\section{Introdução}

- ntende-se que o Estado e a educação são os principais potencializadores do

- desenvolvimento regional. As Organização das Nações Unidas utilizam a longevidade, a renda per capita e o grau de escolaridade para determinar o índice de desenvolvimento humano (Sousa; Freiesleben, 2018).

Segundo Sousa e Freiesleben (2018) é "por meio da aquisição de conhecimentos [que] o indivíduo aumenta sua renda, sua qualidade de vida e consequentemente ocorre 0 crescimento da nação" (p. 167). Diante desse cenário é relevante que o Estado crie políticas públicas de educação que possibilitem ao cidadão ter acesso a formação de qualidade.

A Organização para a Cooperação e Desenvolvimento Econômico tem destacado em seus últimos relatórios que houve um aumento dos investimentos públicos em educação no Brasil (OCDE, 2017). Dentre os investimentos feitos está a expansão da Rede Federal de Educação Profissional, Científica e Tecnológica. Segundo o Ministério da Educação a rede teve a sua maior expansão entre 2003 e 2016, quando o MEC construiu 500 novas unidades de educação profissional e tecnológica em todo território nacional. Fazem parte dessa rede os Institutos Federais de Educação, Ciência e Tecnologia - Ifects -, também chamados de Institutos Federais, que são instituições de educação superior, básica e profissional com foco em educação profissional e tecnológica (Brasil, 2016a, Brasil, 2016b).

Os IFs atuam em diferentes modalidades de ensino: bacharelado, licenciatura e formação tecnológica. A licenciatura, foco desse artigo, é um tipo de curso superior de graduação que habilita o profissional a atuar no magistério na educação básica (Porto, 2018). De acordo com a lei n. 11.892 (Brasil, 2008), é objetivo dos IFs, entre outros, destinar no mínimo $20 \%$ de suas vagas para os cursos de licenciatura. Em contrapartida é esperado que os egressos retribuam devolvendo para a sociedade o conhecimento adquirido. Tem-se a expectativa, portanto, que esses ex-alunos estejam efetivamente atuando em alguma área relacionada ao âmbito educacional.

A presente pesquisa teve como objetivos identificar se os egressos dos cursos de licenciatura do IF Goiano atuam profissionalmente na área de formação acadêmica específica; apontar os motivos que os fizeram cursar uma licenciatura e investigar quais são as perspectivas dos egressos em relação à carreira docente.

O estudo se torna relevante, pois, até o momento não se tem conhecimento de nenhum dado referente à situação dos egressos formados nos cursos de licenciatura do IF Goiano que informe ou esclareça se os egressos licenciados exercem ou não suas atividades profissionais dentro da área de formação acadêmica.

\section{A rede federal de ensino}

No âmbito do sistema federal de ensino as instituições que formam a Rede Federal de Educação Profissional, Científica e Tecnológica são originárias, em grande parte, das 19 escolas de aprendizes artífices, instituídas pelo decreto n. 7.566 (Brasil, 1909). Segundo o MEC (Brasil, 2010a), a criação desse conjunto de escolas tinha como objetivo fornecer oportunidades de qualificação profissional às classes menos favorecidas. 
Essas instituições foram transformadas nos Liceus Industriais em 1937. Em 1942, um ano após o ensino profissional ser considerado de nível médio, por meio do decreto $\mathrm{n}$. 4.127, esses Liceus passaram a se chamar Escolas Industriais e Técnicas (pacheco, 2011).

Em 1978 as escolas federais do Rio de Janeiro, Minas Gerais e Paraná, transformaram-se em Centros Federais de Educação Tecnológica - Cefets -, passando a se equipararem aos centros universitários, o que ajudou a aumentar o número de matrículas e a implantação de novos cursos técnicos (Brasil, 2010a, Pacheco, 2011).

Em 1994, pela lei n. 8.948, instituiu-se o Sistema Nacional de Educação Tecnológica, transformando as Escolas Técnicas Federais em Cefets (BRASIL, 1994). Nesse contexto foram iniciadas as ações para a constituição da Rede Federal de Educação Profissional, Científica e Tecnológica. Em 1997 o decreto n. 2.208 (Brasil, 1997) regulamentou a educação profissional e criou o Programa de Expansão da Educação Profissional (Brasil, 2010a).

No entanto, em 1998, o governo federal proibiu a construção de novas escolas federais e direcionou as instituições existentes para a oferta predominante de cursos superiores. Essa proibição só foi revogada em 2005 (Brasil, 2010a), com a adição da possibilidade da oferta de cursos técnicos integrados ao ensino médio.

No ano de 2007, pelo decreto n. 6.095, estabeleceu-se as diretrizes de integração das instituições federais de educação tecnológica, que deram origem aos Institutos Federais de Educação, Ciência e Tecnologia, compondo assim a Rede Federal de Educação Profissional e Tecnológica (Brasil, 2007).

Por meio da lei n. 11.892, que institui a Rede Federal de Educação Profissional Científica e Tecnológica, vinculada ao MEC, foi criado o Instituto Federal Goiano, junto com outros 37 IFs, a Universidade Tecnológica e Federal do Paraná, os Centros Federais de Educação Tecnológica Celso Suckow da Fonseca e de Minas Gerais, 25 escolas técnicas vinculadas às universidades federais, e o Colégio Pedro II (Brasil, 2008).

\section{O IF Goiano}

De acordo com o disposto na lei n. 11.892, o Estado de Goiás ficou com dois institutos: o Instituto Federal Goiano - IF Goiano - e o Instituto Federal de Goiás - IFG. O IF Goiano agregou os Cefets de Rio Verde, de Urutaí e a Unidade de Ensino Descentralizada de Morrinhos, assim como a Escola Agrotécnica Federal de Ceres (Brasil, 2015f).

O IF Goiano possui oito campi instalados nas cidades de Morrinhos, Urutaí, Rio Verde, Ceres, Campos Belos, Iporá, Posse e Trindade. Além desses tem três campi avançados nas cidades de Catalão, Ipameri e Hidrolândia, o campus em implantação de Cristalina e o Polo de Inovação na cidade de Rio Verde.

O IF Goiano é uma autarquia federal com autonomia didático-pedagógica e disciplinar. O instituto é especializado em educação profissional e tecnológica, oferecendo educação superior, básica, profissional, pluricurricular e multicampi (Brasil, 2015f). No ensino superior atua com cursos tecnológicos, bacharelados e licenciaturas. Mantém 
cursos de pós-graduação, mestrado acadêmico e profissional e um doutorado em Ciências Agrárias. Na educação profissional técnica de nível médio atende os jovens por meio do Programa Nacional de Integração da Educação Profissional integrado com a Educação Básica na Modalidade de Educação de Jovens e Adultos (Brasil, 2015f).

O IF Goiano oferta seis licenciaturas: Matemática, campus Urutaí; Pedagogia, campus Morrinhos; Ciências Biológicas, campus de Ceres, Rio Verde e Urutaí; Química campus de Ceres, Iporá, Morrinhos, Rio Verde e Urutaí; Ciências Naturais, campus Catalão) e segunda licenciatura em Pedagogia, campus Ipameri (Brasil, 2015a). Neste artigo não se aborda o curso de licenciatura em Ciências Naturais, a segunda licenciatura em Pedagogia, e o curso de Química ofertado no Campus Urutaí no período matutino, por ainda não terem nenhuma turma concluída.

O curso de licenciatura em Matemática é ofertado no Campus Urutaí: criado em 2009, com carga horária total de 2.980 horas, duração de 4 anos, modalidade presencial, noturno, 40 vagas anuais por turma (Brasil, 2017c). Segundo o projeto políticopedagógico do curso (Brasil, 2015c), a falta de profissionais voltados para a licenciatura em Matemática, tanto na região de Urutaí quanto em todo o Estado de Goiás, foi uma das principais justificativas para a implantação da licenciatura em matemática nesse campus.

O curso de Licenciatura em Pedagogia é ofertado no campus Morrinhos: criado em 2013, com carga horária de 3.300 horas; duração de 4 anos; modalidade presencial; noturno; 40 vagas anuais por turma (Brasil, 2015d). De acordo com o PPC do curso (Brasil, 2015d), a alta demanda por profissionais com formação em Pedagogia, associada ao fato de que à época de implantação somente instituições particulares ofereciam tal curso na microrregião do Meia Ponte, foram os motivadores da criação do curso no referido campus.

O curso de licenciatura em Ciências Biológicas é ofertado no Campus Ceres: criado em 2009, com carga horária de 3.580 horas; duração de 4 anos; modalidade presencial; noturno; 40 vagas anuais por turma (Brasil, 2018a). Um dos fatores que justificou a implantação do curso de licenciatura em Ciências Biológicas no Campus Ceres, entre outros, decorreu da falta de profissionais da educação básica qualificados para trabalhar disciplinas de Ciências e Biologia e ainda capazes de integrar os conhecimentos de "biotecnologias, produção, saúde e preservação do meio ambiente" (Brasil, 2012).

O curso também é ofertado no campus Rio Verde: criado em 2008 no turno noturno e 2010 no diurno; com carga horária de 3.210 horas; duração de 4 anos; modalidade presencial; noturno e diurno; 40 vagas anuais por turma (Brasil, 2017b). Segundo o PPC do curso (Brasil, 2013a), além do reduzido número de profissionais licenciados em Ciências Biológicas, a justificativa para a sua implantação no campus Rio Verde foi o fato de que a área das Ciências tem se destacado em termos de avanços científicos e tecnológicos relacionados, por exemplo, à biotecnologia, com reflexo sobre diversas outras áreas.

No campus Urutaí o mesmo curso foi criado em 2009, com carga horária de 3.120 horas; duração de 4 anos; modalidade presencial; noturno; 40 vagas anuais por turma (Brasil, 2015b). Um dos fatores que levou o campus a oferecer a licenciatura em Ciências Biológicas é por atender, em maior número, alunos oriundos dos municípios que formam 
a microrregião de Pires do Rio (Brasil, 2015b). Segundo dados do IBGE (Brasil, 2010c), nessa microrregião, no ano de 2010 foram realizadas aproximadamente 5.883 matrículas no ensino médio, sinalizando assim a necessidade de ofertar cursos superiores na região para atender tal demanda.

O curso de licenciatura em Química é ofertado:

- no campus Ceres: criado em 2011,com carga horária de 3.220 horas; duração de 4 anos; modalidade presencial; noturno; 40 vagas anuais por turma (Brasil, 2018b). De acordo com o PPC (Brasil, 2013b) da referida licenciatura, o déficit de profissionais na área de Química, aliado ao grande número de concluintes do ensino médio, tanto no município de Ceres, quanto em suas cidades vizinhas, motivou a implantação dessa licenciatura no campus.

- no campus Iporá: criado em 2011, com carga horária de 3.200 horas; duração de 4 anos; modalidade presencial; noturno; 40 vagas anuais por turma (Brasil, 2017a). O curso de licenciatura em Química no campus Iporá foi implantado, entre outros fatores, como forma de potencializar o uso da estrutura física e de recursos humanos que o campus já possuía. Outro importante motivo que justificou a oferta dessa licenciatura no campus Iporá decorre do empenho da instituição em seguir a proposta de verticalizar o ensino, possibilitando ao discente a formação continuada numa mesma área de atuação, visto que o campus já oferta o curso de Técnico de Química integrado ao ensino médio (Brasil, 2013c).

- no campus Morrinhos: criado em 2010, com carga horária de 3.203 horas; duração de 4 anos; modalidade presencial; noturno; 40 vagas anuais por turma (Brasil, 2015g). De acordo com o PPC (Brasil, 2015e) do curso uma das principais justificativas para a implantação desse curso no referido campus decorre da escassez de professores licenciados em Química na região, sendo que as únicas instituições de ensino que ofertavam tal licenciatura na região, até o momento da implantação desse curso, estavam localizadas a mais de $90 \mathrm{~km}$ de distância da cidade de Morrinhos.

- no campus Rio Verde: criado em 2008, com carga horária de 2.990 horas; duração de 4 anos; modalidade presencial; noturno; 40 vagas anuais por turma (Brasil, 2010b). Segundo o PPC do curso (Brasil, 2010b), um dos principais fatores que justificaram a implantação desse curso no referido campus foi em função da instituição visualizar o aproveitamento da estrutura e quadro de professores. O campus Rio Verde já possuía, por exemplo, infraestrutura física formada por laboratórios de solos, informática aplicada, análise de sementes, microbiologia, fitopatologia, entomologia, biotecnologia, controle de sanidade animal, bromatologia, química, águas e afluentes.

- no campus Urutaí: criado em 2011, com carga horária de 3.098 horas; duração de 4 anos; modalidade presencial; matutino e noturno; 40 vagas anuais por turma (Brasil, 2013d, Brasil, 2017d). Segundo o PPC (BRASIL, 2013d) um dos principais motivos para a implantação do curso nesse campus foi em função da grande carência de professores licenciados em Química na área da educação.

Do exposto até o momento, pode-se dizer que a demanda por pessoas capacitadas para trabalhar no ensino básico foi o principal motivador da criação dos cursos de licenciatura do IF Goiano. Pelo quadro 1 sumariza-se as características dos cursos de licenciatura oferecidos. Percebe-se que o IF Goiano tem condições de, a cada ciclo de quatro anos, ajudar a suprir o déficit de profissionais da educação básica pela formação 
de cerca de 600 licenciados habilitados nas áreas de alta demanda. Esses profissionais podem ser alocados em muitas cidades do interior do Estado de Goiás, nas disciplinas de Ciências, Química, Biologia, no ensino médio ou fundamental.

Quadro 1 -

Licenciaturas oferecidas pelo IF Goiano.

\begin{tabular}{|l|l|l|c|c|c|c|c|}
\hline \multicolumn{1}{|c|}{ Curso } & Campus & Criação & $\begin{array}{c}\text { Carga } \\
\text { horária }\end{array}$ & $\begin{array}{c}\text { Duração } \\
\text { (anos) }\end{array}$ & Modalidade & Turno & Vagas \\
\hline Matemática & Urutaí & 2009 & 2.980 & 4 & Presencial & Noturno & 40 \\
\hline Pedagogia & Morrinhos & 2013 & 3.300 & 4 & Presencial & Noturno & 40 \\
\hline \multirow{4}{*}{$\begin{array}{l}\text { Ciências } \\
\text { Biológicas }\end{array}$} & Ceres & 2009 & 3.580 & 4 & Presencial & Noturno & 40 \\
\cline { 2 - 8 } & Rio Verde & 2008 & 3.210 & 4 & Presencial & Noturno & 40 \\
\cline { 2 - 8 } & Urutaí & 2010 & 3.210 & 4 & Presencial & Diurno & 40 \\
\hline \multirow{4}{*}{ Química } & Ceres & 2009 & 3.120 & 4 & Presencial & Noturno & 40 \\
\cline { 2 - 9 } & Iporá & 2011 & 3.220 & 4 & Presencial & Noturno & 40 \\
\cline { 2 - 9 } & Morrinhos & 2010 & 3.200 & 4 & Presencial & Noturno & 40 \\
\cline { 2 - 9 } & Rio Verde & 2008 & 2.990 & 4 & Presencial & Noturno & 40 \\
\cline { 2 - 8 } & Urutaí & 2011 & 3.098 & 4 & Presencial & Noturno & 40 \\
\hline
\end{tabular}

Fonte: autores (2019).

\section{Metodologia}

A pesquisa abrangeu 93 egressos oriundos das turmas iniciadas no ano de $2013 \mathrm{e}$ 2014 dos cursos de licenciatura em Matemática, Pedagogia, Ciências Biológicas e Química do IF Goiano. Ressalta-se que essas turmas iniciadas foram concluídas até no máximo no ano de 2017; com exceção do curso noturno de licenciatura em Ciências Biológicas do campus Ceres, que teve turma iniciada no $2^{\circ}$ semestre de 2014 e conclusão no $1^{\circ}$ semestre de 2018.

A pesquisa caracteriza-se como um estudo exploratório, descritivo, com abordagem quantitativa. Exploratória, pois, conforme afirma Gil (2007), esse tipo de pesquisa tem o objetivo de explicitar o problema buscando compreender o fenômeno estudado. É uma pesquisa descritiva, pois, buscou-se descrever os fatos observados através da análise de dados quantitativos oriundos de questionários e análise documentos.

Esse trabalho também utilizou pesquisas bibliográfica e documental. Bibliográfica, pois, foi essencial para o desenvolvimento da pesquisa o levantamento de referências teóricas publicadas tanto por meio escrito quanto eletrônico, leituras em websites, livros, artigos, revistas científicas, periódicos, leis, decretos, pareceres, resoluções, entre outras fontes, permitindo assim o conhecimento acerca do tema abordado. Além de bibliográfica enquadra-se também como documental, pois foram utilizados como fonte de informação, de forma indispensável, determinados documentos institucionais, os quais constituíram fontes estáveis e plenas de dados para o presente estudo. De tal modo, foram utilizados como fonte de consulta dados fornecidos pela Pró-Reitoria de Ensino do IF Goiano e por diretorias de Ensino dos campi do IF Goiano que ofertam cursos de licenciatura, documentos oficiais diversos, materiais didáticos dos cursos, PPCs, entre outros documentos oficiais produzidos pela instituição pertinentes à pesquisa. 
A pesquisa utilizou dados primários, obtidos por informações captadas por meio de questionário. Esses foram relacionados com os dados obtidos das fontes secundárias captados através das pesquisas documental e bibliográfica.

Como instrumento de coleta de dados a pesquisa utilizou um questionário eletrônico composto por 31 questões, com perguntas abertas, fechadas e de múltipla escolha. Durante a elaboração do questionário houve a preocupação com relação a disposição das perguntas e a extensão do questionário, bem como buscou-se empregar uma linguagem clara e objetiva, para facilitar o entendimento das questões apresentadas aos egressos.

\section{Egressos do IF Goiano}

De acordo com o sistema de gestão dos processos administrativos e acadêmicos do IF Goiano, considerando as turmas iniciadas no ano de 2013 e 2014, formaram nos cursos de licenciatura do IF Goiano 137 egressos dos cursos de licenciatura do IF Goiano de Matemática do campus Urutaí (noturno); Pedagogia do campus Morrinhos (noturno); Ciências Biológicas dos campi Ceres (noturno), Rio Verde (diurno e noturno) e Urutaí (noturno); e Química dos campi Ceres (noturno), Iporá (noturno), Morrinhos (noturno), Rio Verde (noturno) e Urutaí (noturno).

Quadro 2 -

Egressos dos cursos de licenciatura IF Goiano das turmas iniciadas em 2013 e 2014.

\begin{tabular}{|c|c|c|c|c|c|c|}
\hline Curso & Campus & Ingresso & Conclusão & Egressos & $\begin{array}{l}\text { Total de } \\
\text { egresso } \\
\text { s curso }\end{array}$ & Ingressantes \\
\hline \multirow{2}{*}{ Matemática } & \multirow{2}{*}{ Urutaí } & 2013 & 2016 & 14 & \multirow{2}{*}{15} & 52 \\
\hline & & 2014 & 2017 & 1 & & 23 \\
\hline \multirow{2}{*}{ Pedagogia } & \multirow{2}{*}{ Morrinhos } & 2013 & 2016 & 13 & \multirow{2}{*}{22} & 42 \\
\hline & & 2014 & 2017 & 9 & & 36 \\
\hline \multirow{7}{*}{$\begin{array}{l}\text { Ciências } \\
\text { Biológicas }\end{array}$} & \multirow{2}{*}{ Ceres } & 2013 & 2017 & 12 & \multirow{2}{*}{17} & 39 \\
\hline & & 2014 & 2018 & 5 & & 45 \\
\hline & \multirow{3}{*}{ Rio Verde } & 2013 & 2016 & 2 & 02 & 16 \\
\hline & & 2013 & 2016 & 7 & \multirow{2}{*}{12} & 63 \\
\hline & & 2014 & 2017 & 5 & & 46 \\
\hline & \multirow{2}{*}{ Urutaí } & 2013 & 2016 & 10 & \multirow{2}{*}{20} & 45 \\
\hline & & 2014 & 2017 & 10 & & 39 \\
\hline \multirow{10}{*}{ Química } & \multirow{2}{*}{ Ceres } & 2013 & 2016 & 6 & \multirow{2}{*}{10} & 32 \\
\hline & & 2014 & 2017 & 4 & & 38 \\
\hline & \multirow{2}{*}{ Iporá } & 2013 & 2016 & 8 & \multirow{2}{*}{18} & 31 \\
\hline & & 2014 & 2017 & 10 & & 36 \\
\hline & \multirow{2}{*}{ Morrinhos } & 2013 & 2016 & 1 & \multirow{2}{*}{03} & 33 \\
\hline & & 2014 & 2017 & 2 & & 22 \\
\hline & \multirow{2}{*}{ Rio Verde } & 2013 & 2016 & 4 & \multirow{2}{*}{08} & 53 \\
\hline & & 2014 & 2017 & 4 & & 52 \\
\hline & \multirow{2}{*}{ Urutaí } & 2013 & 2016 & 7 & \multirow{2}{*}{10} & 36 \\
\hline & & 2014 & 2017 & 3 & & 22 \\
\hline \multicolumn{4}{|l|}{ Total } & 137 & 137 & 801 \\
\hline
\end{tabular}

Fonte: autores (2019). 
Durante o tempo de coleta de dados via questionário, de 26/12/2018 a 26/01/2019, responderam as perguntas 93 egressos, o que corresponde a $67,9 \%$ do total geral de egressos.

\section{Resultados e discussões}

Nesta seção são apresentados os resultados, a análise dos dados e das informações obtidas. São apresentados também a descrição do perfil sócio-demográfico dos egressos (sexo, faixa etária, residência, escolaridade, formação); sua atuação e perfil profissional, tanto antes e durante a licenciatura; as formas de ingresso no mundo do trabalho; o perfil do atual local de trabalho; as principais motivações que influenciaram os egressos a cursar uma licenciatura; as expectativas em relação ao mercado de trabalho para o professor e em relação à carreira docente; seu interesse quanto à formação continuada; além da caracterização do processo de inserção profissional no mundo do trabalho.

Constatou-se que os egressos das licenciaturas do IF Goiano são predominantemente constituídos por mulheres, sendo que dos 93 respondentes, 73 egressos, o que corresponde a $78,5 \%$ da amostra são do sexo feminino, enquanto que 20 egressos, o que corresponde a $21,5 \%$ da amostra são do sexo masculino.

Dos respondentes $81,7 \%$ é predominantemente jovem, estando entre 20 a 29 anos, sendo a maior parcela destes representada por indivíduos de 20 a 24 anos. De forma detalhada, entre os egressos, têm-se $61 \mathrm{com}$ idade de 20 a 24 anos, 15 egressos têm idade de 25 a 29 anos, 8 egressos têm idade de 30 a 34 anos e 9 egressos têm idade de 35 anos ou mais.

Quando perguntados onde residiam antes de concluírem a licenciatura, 85 indivíduos $(91,4 \%)$ informaram que residiam em cidades do Estado de Goiás. Quando questionados sobre o local de residência atual constatou-se que a maioria dos egressos ainda reside em algum município goiano, sendo percentual de resposta o mesmo, ou seja $91,4 \%$ da amostra continuou residindo no Estado de Goiás após a conclusão do curso. Assim, percebe-se que as vagas dos cursos de licenciatura ofertadas pelo IF Goiano estão sendo preenchidas majoritariamente pelos próprios estudantes do Estado de Goiás.

Quando questionados sobre seu nível de escolaridade atual a maioria dos egressos informou que não cursou ou não está cursando alguma pós-graduação. Dos 93 respondentes 21 egressos, o que corresponde a $22,6 \%$ da amostra, cursaram ou estão cursando alguma pós-graduação. Desses sete egressos responderam especialização, 13 responderam mestrado e um respondeu doutorado.

Tabela 1 -

Nível de escolaridade atual.

\begin{tabular}{l|c|c}
\hline \multicolumn{1}{c|}{ Pós-graduação } & Quantidade & $\%$ \\
\hline Não cursou & 72 & 77,4 \\
\hline Especialização & 7 & 7,5 \\
\hline Mestrado & 13 & 14,0 \\
\hline Doutorado & 1 & 1,1 \\
\hline Total & 93 & 100,0 \\
\hline
\end{tabular}

Fonte: autores (2019). 
Para aqueles que responderam que cursaram ou estão cursando alguma pósgraduação - 21 egressos - foi questionado se a IES seria pública ou privada, de modo que 15 respondentes informaram ter estudado ou estar estudando em uma IES pública; enquanto seis indivíduos informaram ter estudado ou estar estudando em uma IES privada, um respondente não informou onde estudou ou está estudando. Nota-se que a continuidade da formação acadêmica dos egressos do IF Goiano depois de concluir os cursos de licenciatura ocorreu ou está ocorrendo em IES pública.

Pelas respostas observou-se que, predominantemente, os egressos não buscaram uma outra graduação depois de concluída a licenciatura no IF Goiano. Dos 93 egressos, 88 respondentes, o que corresponde a $94,6 \%$ da amostra, não estão cursando outra graduação, enquanto cinco respondentes estão cursando outra graduação.

Quando questionados se atuavam na área da educação básica antes ou durante sua formação na licenciatura do IF Goiano a maioria, 71 egressos, o que corresponde a 76,3\% da amostra, informaram que não trabalhava na área de educação básica antes ou durante sua formação superior.

Já quando questionados se atualmente estariam trabalhando na área da educação básica dos 93 egressos que responderam o questionário, 31 egressos, o que corresponde a 33,3\% da amostra, informaram que atualmente trabalham na área de educação básica. No entanto, a maioria, 62 egressos, o que corresponde a 66,7\% da amostra, informaram que não trabalham na área de educação básica no momento. Desses 62 egressos que não trabalham na área de educação básica atualmente, 32 respondentes estão desempregados e 30 indivíduos trabalham em áreas diversas à sua formação acadêmica.

Comparando o número de egressos que trabalhava na área de educação básica antes ou durante sua formação superior - 22 egressos - com o número de egressos que passaram a trabalhar depois de graduados - 31 egressos -, nota-se que ocorreu um discreto crescimento em relação a atuação profissional. Houve um aumento de 9,6\% na quantidade de egressos que passaram a trabalhar na educação básica após concluir o curso de licenciatura em relação àqueles que atuavam na educação básica antes ou durante sua formação superior.

Dos 32 egressos que atualmente se encontram desempregados a maioria informou que não está trabalhando devido principalmente a dois motivos: falta de demanda na área de formação e em virtude da baixa remuneração para profissionais na área de formação.

Conforme mostra a tabela 2 , dos 32 egressos que informaram não estar trabalhando no momento, 13 respondentes informaram que não estão trabalhando devido à falta de demanda na área de formação, 12 respondentes informaram que não estão trabalhando devido a outros motivos, sete respondentes informaram que não estão trabalhando em virtude da baixa remuneração para profissionais na área de formação e nenhum egresso escolheu a opção "devido à escolha vocacional equivocada".

Dessa forma, infere-se que, mesmo diante da falta de oportunidade na área de formação do licenciado, nenhum egresso acredita que se equivocou em sua escolha vocacional, ou seja, nenhum egresso demonstrou ter se arrependido de cursar licenciatura. 
Tabela 2 -

Motivos que os egressos informaram para justificar o desemprego.

\begin{tabular}{l|c|c}
\hline \multicolumn{1}{c|}{ Motivo } & Quantidade & $\%$ \\
\hline Remuneração baixa & 7 & 21,9 \\
\hline Falta de demanda na área & 13 & 40,6 \\
\hline $\begin{array}{l}\text { Escolha vocacional } \\
\text { equivocada }\end{array}$ & 0 & 0 \\
\hline Outros motivos & 12 & 37,5 \\
\hline \multicolumn{1}{c}{ Total } & 32 & 100,0 \\
\hline
\end{tabular}

Fonte: autores (2019).

Conforme já exposto, 31 egressos responderam que atualmente trabalham na área da educação básica. A esses indivíduos foi perguntado qual o cargo que ocupam na área, sendo que 18 egressos informaram que atualmente trabalham lecionando em algum curso de sua área de formação, enquanto que 13 respondentes disseram que atualmente não trabalham lecionando em algum curso de sua área de formação.

Observou-se ainda que dos 31 egressos que informaram que atualmente estão trabalhando na educação básica, a maioria informou que ocupa o cargo de professor, conforme pode ser visto na tabela 3. Desses 31 egressos que estão ocupando atualmente algum cargo na área da educação básica, 27 respondentes atualmente ocupam cargo de professor, três ocupam cargos diversos e um não informou qual cargo está ocupando atualmente.

Tabela 3 -

Cargos dos egressos atualmente trabalhando na educação básica.

\begin{tabular}{l|c|c}
\hline \multicolumn{1}{c|}{ Cargos } & Quantidade & $\%$ \\
\hline Cargo de professor & 27 & 87,1 \\
\hline $\begin{array}{l}\text { Cargos diversos na } \\
\text { educação básica }\end{array}$ & 3 & 9,7 \\
\hline Cargo não informado & 1 & 3,2 \\
\hline \multicolumn{1}{c|}{ Total } & 31 & 100,0 \\
\hline
\end{tabular}

Fonte: autores (2019).

Além disso foi questionado àqueles egressos que atualmente estão trabalhando na educação básica qual foi o intervalo de tempo levado entre a conclusão da licenciatura e a admissão na educação básica. Dos 31 respondentes, a maioria - 26 indivíduos - adentrou no mercado de trabalho nessa área em até seis meses depois de concluído o curso de licenciatura.

Pode-se notar que para parte desses egressos que atualmente trabalham na educação básica, sua entrada no mercado de trabalho na área de formação após a conclusão da graduação ocorreu em um período de tempo relativamente curto. O que permite inferir que o fato de ter concluído a graduação contribuiu para sua entrada no mercado de trabalho em sua área de formação específica em um curto prazo de tempo. 
Tabela 4 -

Tempo entre a conclusão da licenciatura e a admissão na educação.

\begin{tabular}{l|c|c}
\hline \multicolumn{1}{c|}{ Tempo } & Quantidade & $\%$ \\
\hline Até 6 meses & 26 & 84,0 \\
\hline De 6 meses a 1 ano & 3 & 10,0 \\
\hline De 1 a 2 anos & 1 & 3,0 \\
\hline Acima de 2 anos & 1 & 3,0 \\
\hline \multicolumn{1}{c|}{ Total } & 31 & 100,0 \\
\hline
\end{tabular}

Fonte: autores (2019).

Foi investigado também a caracterização das escolas que estão absorvendo profissionalmente os egressos. Observou-se que a maioria trabalha em escolas da rede pública, principalmente, estadual/distrital - 19 respondentes - e municipal - 10 respondentes. Observou-se que a maioria trabalha em escolas ofertantes de ensino fundamental - 24 respondentes - e ensino médio - 16 respondentes -, sendo que as escolas onde os egressos atuam se encontram situadas majoritariamente na zona urbana - 30 respondentes - e localizadas no Estado de Goiás - 25 respondentes.

Tabela 5 -

Cargos dos egressos atualmente trabalhando na educação básica.

\begin{tabular}{c|c|c}
\hline \multicolumn{1}{c|}{ Rede } & Quantidade & $\%$ \\
\hline Pública estadual/distrital & 19 & 61,3 \\
\hline Pública municipal & 10 & 32,3 \\
\hline Particular & 2 & 6,4 \\
\hline \multicolumn{1}{c|}{ Total } & 31 & 100,0 \\
\hline
\end{tabular}

Fonte: autores (2019).

Quando questionados sobre as motivações para ter cursado uma licenciatura a maioria dos egressos respondeu que foi motivada a cursar uma licenciatura principalmente por dois motivos: por vocação e por influência dos pais, familiares ou terceiros. Dos 93 respondentes, 42 egressos, o que corresponde a 45,2\% da amostra, foram motivados a cursar uma licenciatura por vocação; 36 egressos, o que corresponde a $38,7 \%$ da amostra, foram motivados a cursar uma licenciatura por influência dos pais, familiares ou terceiros, 24 egressos, o que corresponde a 25,8\% da amostra, tiveram outras motivações, 9 egressos, o que corresponde a 9,7\% da amostra, foram motivados a cursar uma licenciatura pelo prestígio social que a função proporciona e seis egressos, o que corresponde a $6,5 \%$ da amostra, foram motivados a cursar uma licenciatura pelo retorno financeiro da profissão. Ressalta-se que nessa questão o egresso poderia marcar mais de uma alternativa, tendo a liberdade de selecionar quantas opções achasse necessário.

Quando questionados sobre suas expectativas em relação ao mercado de trabalho um pouco menos da metade dos egressos, mas ainda assim a maioria em relação às demais alternativas dadas como resposta, informou ter expectativas positivas. Dos 93 respondentes 9 egressos, o que corresponde a 9,7\% da amostra, têm expectativas altamente positivas em relação ao mercado de trabalho para o professor; 42 egressos, o 
que corresponde a $45,2 \%$ da amostra, têm expectativas positivas em relação ao mercado de trabalho para o professor, 30 egressos, o que corresponde a $32,3 \%$ da amostra, têm expectativas pouco positivas em relação ao mercado de trabalho para o professor e 12 egressos, o que corresponde a 12,9\% da amostra, têm expectativas nada positivas em relação ao mercado de trabalho para o professor.

Quanto às perspectivas em relação à carreira docente a maioria dos egressos informou serem promissoras. Dos 93 respondentes seis egressos disseram que têm perspectivas altamente promissoras em relação à carreira docente, 57 egressos têm perspectivas promissoras em relação à carreira docente, 24 egressos têm perspectivas pouco promissoras em relação à carreira docente, e seis egressos tem perspectivas nada promissoras em relação à carreira docente.

Ainda em se tratando das expectativas dos egressos em relação à carreira docente, observou-se que dos 93 respondentes a maioria acredita que a carreira docente lhe trouxe ou trará ao longo dos anos, principalmente a realização ou prestígio profissional e realização ou prestígio pessoal. Dos 93 respondentes 51 egressos, o que corresponde a $54,8 \%$ da amostra, acreditam que a carreira docente lhe trouxe ou trará ao longo os anos realização ou prestígio profissional, 39 egressos, o que corresponde a 41,9\% da amostra, acreditam que a carreira docente the trouxe ou trará ao longo dos anos realização ou prestígio pessoal, 24 egressos, o que corresponde a $25,8 \%$ da amostra, acreditam que a carreira docente lhe trouxe ou trará ao longo os anos retorno financeiro satisfatório, 21 egressos, o que corresponde a $22,6 \%$ da amostra, acreditam que a carreira docente lhe trouxe ou trará ao longo os anos retorno financeiro pouco satisfatório, 9 respondentes, o que corresponde a 9,7\% desses egressos, respondeu "outros" e nenhum egresso acredita que a carreira docente lhe trouxe ou trará ao longo dos anos retorno financeiro muito satisfatório. Ressalta-se que nessa questão o egresso também poderia marcar mais de uma alternativa, tendo a liberdade de selecionar quantas opções achasse necessário.

$\mathrm{Na}$ tabela 6 se sumariza as expectativas e vocação dos egressos em licenciatura. Percebe-se pelos destaques feito na tabela que a maioria assinalou que possui vocação para a área e buscam realização ou prestígio profissional, possuindo expectativas positivas em relação ao mercado e a carreira.

Tabela 6 -

Sumarização das expectativas e vocação dos egressos.

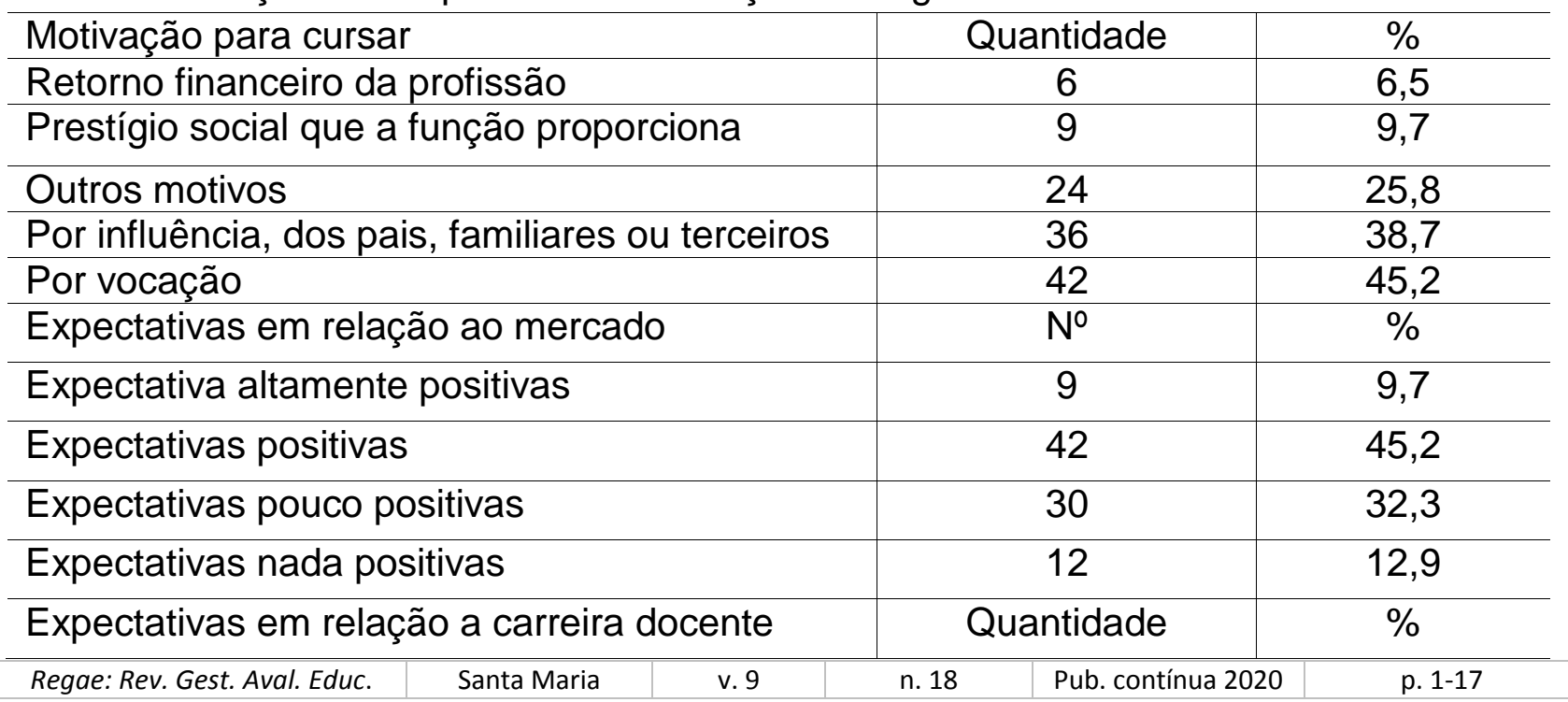




\begin{tabular}{l|c|c}
\hline Expectativa altamente promissoras & 6 & 6,5 \\
\hline Expectativas promissoras & 57 & 61,3 \\
\hline Expectativa pouco promissora & 24 & 25,8 \\
\hline Expectativa nada promissora & 6 & 6,5 \\
\hline Expectativas em relação ao retorno da carreira & Quantidade & $\%$ \\
\hline Realização ou prestígio profissional & 51 & 54,8 \\
\hline Realização ou prestígio pessoal & 39 & 41,9 \\
\hline Retorno financeiro satisfatório & 24 & 25,8 \\
\hline Retorno financeiro pouco satisfatório & 21 & 22,6 \\
\hline Retorno financeiro muito satisfatório & 0 & 0 \\
\hline Outros & 9 & 9,7 \\
\hline
\end{tabular}

Fonte: Próprios (2019).

\section{Considerações finais}

Os dados obtidos por meio dos questionários permitiram traçar o perfil dos egressos oriundos das turmas iniciadas no ano de 2013 e 2014 dos cursos de licenciatura do IF Goiano, indicando que esses são compostos, principalmente, por mulheres: $78,5 \%$ da amostra; jovens com idade entre 20 a 29 anos: $81,7 \%$ da amostra; estudantes originários de municípios goianos: 91,4\% da amostra; que atualmente, depois de concluída a licenciatura, continuam residindo no Estado de Goiás: 91,4\% da amostra. No que tange à formação continuada a maioria não cursou ou não está cursando pós-graduação: $77,4 \%$ da amostra; e também não cursou ou não está cursando uma segunda graduação: 94,6\% da amostra.

De acordo com os dados apresentados é possível inferir que as vagas dos cursos de licenciatura ofertadas pelo IF Goiano estão sendo preenchidas majoritariamente pelos próprios estudantes goianos após concluírem o ensino médio nos municípios do Estado e que, depois de graduados pelo IF Goiano, continuam fixados no Estado de Goiás.

Em se tratando do questionamento principal da pesquisa - identificar se os egressos oriundos das turmas iniciadas no ano de 2013 e 2014 dos cursos de licenciatura do IF Goiano estão trabalhando como professores depois de concluído o curso -, observou-se que a maioria dos egressos não trabalha na educação básica depois de concluído os cursos de licenciatura no IF Goiano. Diante de tais dados depreende-se, que para esta amostra estudada, grande parte do empenho despendido pelo IF Goiano na abertura e manutenção de cursos de licenciatura das turmas de 2013 e 2014 não proporcionou ainda o retorno esperado, mesmo que por motivos alheios ao controle da instituição.

Ao ofertar cursos de licenciatura o IF Goiano promove um amplo investimento social e econômico na gestão dessa oferta como, por exemplo, abertura de concursos públicos para contratação de servidores professores e técnicos administrativos; manutenção das estruturas físicas; compra e fornecimento de material didático, merenda e uniformes escolares; gerenciamento de contratos e licitações, entre outros. Dessa forma, é possível inferir que, até o momento, o retorno esperado para a sociedade do investimento oferecido pelo Estado e recebido pelos egressos dessa amostra durante sua formação acadêmico-profissional ainda é baixo, visto que depois de formados esses egressos não estão atuando na sua área de formação profissional. 
No entanto, a pesquisa não é conclusiva em relação à qualidade do ensino ofertado ou ao tipo de formação que está sendo oferecido pelo IF Goiano, uma vez que tais resultados apresentados possivelmente podem ser conjecturais. Para ser conclusivo, seria necessário, em trabalhos futuros, comparar os dados e informações obtidas nesta pesquisa com a realidade de cada região onde se encontram esses egressos, por exemplo, em relação à demanda e ao mercado de trabalho local para determinado tipo de licenciatura/profissão, entre outros aspectos relacionados a cada uma das licenciaturas pesquisadas.

Propõe-se, então, um diálogo maior da instituição com as escolas de educação básica, principalmente, com as escolas públicas dos municípios onde se localizam os campi do IF Goiano, com vistas à uma maior integração com essas escolas, bem como desenvolver medidas e ações a fim de ampliar as vagas disponíveis na área da educação, por meio da criação de novos postos de trabalho. Conforme os dados obtidos na pesquisa, além dessas escolas serem um dos principais locais de trabalho do professor, observou-se nelas um maior contingente de egressos do IF Goiano trabalhando logo depois de formados, destacando assim sua importância.

Por fim, este estudo aborda um tema desafiador envolvendo um assunto de importância social. Em termos práticos os resultados destacaram a importância dos cursos de licenciatura e do professor, tanto para o IF Goiano, quanto para a sociedade, além de demonstrar sua importante participação no desenvolvimento regional do CentroOeste. Foram capturados dados que definem o perfil do egresso dos cursos de licenciatura do IF Goiano, demonstrando suas expectativas e sentimentos em relação à carreira profissional.

\section{Referências}

BRASIL. Decreto n. 7.566, de 23 de setembro de 1909. CREA nas capitais dos estados da república escolas de aprendizes artífices, para o ensino profissional primário e gratuito. Rio de Janeiro, (1909). Disponível em http://www2.camara.leg.br/legin/fed/decret/19001909/decreto-7566-23-setembro-1909-525411-publicacaooriginal-1-pe.html. Acesso em 23 jul.2017.

BRASIL. Lei n. 8.948, de 8 de dezembro de (1994). Dispõe sobre a instituição do Sistema Nacional de Educação Tecnológica e dá outras providências. Brasília (1994). Disponível em http://www.planalto.gov.br/ccivil 03/LEIS/L8948.htm. Acesso em 1ํo nov. 2018.

BRASIL. Decreto n. 2.208, de 17 de abril de 1997. Regulamenta o $\S 2$ 으 do art. 36 e os arts. 39 a 42 da lei n. 9.394, de 20 de dezembro de 1996, que estabelece as diretrizes e bases da educação nacional. Brasília, (1997). Disponível em http://www.planalto.gov.br/ccivil 03/decreto/D2208.htm. Acesso em 1ํㅡ. nov. 2018.

BRASIL. Decreto n.6.095, de 24 de abril de 2007. Estabelece diretrizes para o processo de integração de instituições federais de educação tecnológica, para fins de constituição dos institutos federais de educação, ciência e tecnologia no âmbito da Rede Federal de Educação Tecnológica. Brasília, (2007). Disponível em http://www.planalto.gov.br/ccivil 03/ Ato2007-2010/2007/Decreto/D6095.htm. Acesso em 23 julho 2018.

BRASIL. Lei n. 11.892, de 29 de dezembro de 2008. Institui a rede federal de educação profissional, científica e tecnológica, cria os institutos federais de educação, ciência e tecnologia, e dá outras providências. Brasília, (2008). Disponível em 
http://www.planalto.gov.br/ccivil 03/ ato2007-2010/2008/lei/l11892.htm. Acesso em 27 julho 2017.

BRASIL. Um novo modelo em educação profissional e tecnológica. (2010a). Disponível em http://portal.mec.gov.br/component/docman/?task=doc download\&gid=6691\&ltemid=. Acesso em 5 jul. 2017.

BRASIL. Instituto Federal de Educação, Ciência e Tecnologia Goiano (IF Goiano). Projeto político-pedagógico do curso de licenciatura em química do Campus Rio Verde. Rio Verde. (2010b). Disponível em https://www.ifgoiano.edu.br/home/images/RV/CURSOS SUPERIORES/LICENCIATURA QUIMICA/Projeto do Curso de Qumica.pdf. Acesso em 14 ago. 2018.

BRASIL. Instituto Nacional de Estudos e Pesquisas Educacionais Anísio Teixeira (Inep). Sistema de Consulta a Matrícula do Censo Escolar-1997/2015. (2010c). Disponível em http://matricula.educacenso.inep.gov.br/. Acesso em 17 nov. 2018.

BRASIL. Instituto Federal de Educação, Ciência e Tecnologia Goiano (IF Goiano). Projeto político-pedagógico do curso de licenciatura em ciências biológicas do Campus Ceres. (2012). Disponível em https://www.ifgoiano.edu.br/home/images/CER/Doc cursos/PPC Ceres Cincias Biolgica s.pdf. Acesso em 10 ago. 2018.

BRASIL. Instituto Federal de Educação, Ciência e Tecnologia Goiano (IF Goiano). Projeto político-pedagógico do curso de licenciatura em ciências biológicas do Campus Rio Verde. (2013a). Disponível em https://www.ifgoiano.edu.br/home/images/RV/Diretoria de Ensino/PPC LIC.Ci.Biologicas -2013.pdf. Acesso em 10 ago. 2018.

BRASIL. Instituto Federal de Educação, Ciência e Tecnologia Goiano (IF Goiano). Projeto político-pedagógico do curso de licenciatura em química do Campus Ceres. Ceres. (2013b). Disponível em https://www.ifgoiano.edu.br/home/images/CER/Doc cursos/Superior/PPC Qumica 2013. pdf. Acesso em 14 ago. 2018.

BRASIL. Instituto Federal de Educação, Ciência e Tecnologia Goiano (IF Goiano). Projeto político-pedagógico do curso de licenciatura em química do Campus Iporá. Iporá. (2013c). Disponível em https://suap.ifgoiano.edu.br/media/documentos/arquivos/ppc quimica.pdf. Acesso em 14 ago. 2018.

BRASIL. Instituto Federal de Educação, Ciência e Tecnologia Goiano (IF Goiano). Projeto político-pedagógico do curso de licenciatura em química do Campus Urutaí-noturno. Urutaí. (2013d). Disponível em https://www.ifgoiano.edu.br/home/images/URT/ProjetoPedaggico-do-Curso---Noturno.pdf. Acesso em 14 ago. 2018.

BRASIL. Instituto Federal de Educação, Ciência e Tecnologia Goiano (IF Goiano). Cursos $\begin{array}{lll}\text { superiores. } & \text { (2015a). Disponível } & \text { em }\end{array}$ https://www.ifgoiano.edu.br/home/index.php/superiores.html. Acesso em 1ํago. 2018.

BRASIL. Instituto Federal de Educação, Ciência e Tecnologia Goiano (IF Goiano). Projeto político-pedagógico do curso de licenciatura em ciências biológicas do Campus Urutaí. (2015b). Disponível em https://www.ifgoiano.edu.br/home/images/PPC-Licencitura--Biologia---Urutai--Versao-final-2.pdf. Acesso em 9 agosto 2018. 
BRASIL. Instituto Federal de Educação, Ciência e Tecnologia Goiano (IF Goiano). Projeto político-pedagógico do curso de licenciatura em matemática do Campus Urutaí. Urutaí. (2015c). Disponível em https://www.ifgoiano.edu.br/home/images/URT/PDF/PPC Matemtica .pdf. Acesso em 1ํㅜㄴ ago. 2018.

BRASIL. Instituto Federal de Educação, Ciência e Tecnologia Goiano (IF Goiano). Projeto político-pedagógico do curso de licenciatura em pedagogia do Campus Morrinhos. Morrinhos. $\quad$ (2015d). Disponível em https://www.ifgoiano.edu.br/home/images/MHOS/Doc cursos/PPC Pedagogia Novo Con selhoSuperior.pdf. Acesso em 15 jul. 2017.

BRASIL. Instituto Federal de Educação, Ciência e Tecnologia Goiano (IF Goiano). Projeto político-pedagógico do curso de licenciatura em química do Campus Morrinhos. Morrinhos. (2015e). Disponível em https://www.ifgoiano.edu.br/home/images/MHOS/Doc cursos/PPC QUI MORRINHOS.pd f. Acesso em 16 ago. 2018.

BRASIL. Instituto Federal de Educação, Ciência e Tecnologia Goiano (IF Goiano). Saiba mais sobre 0 IF Goiano. (2015f). Disponível em https://www.ifgoiano.edu.br/home/index.php/historico.html. Acesso em 1ํ mar. 2018.

BRASIL. Instituto Federal de Educação, Ciência e Tecnologia Goiano (IF Goiano). Campus Morrinhos. Química. Morrinhos. (2015g). Disponível emhttps://www.ifgoiano.edu.br/home/index.php/cursos-superiores-morrinhos/233-

quimica.html. Acesso em 14 ago. 2018.

BRASIL. Expansão da rede federal. (2016a). Disponível em http://redefederal.mec.gov.br/expansao-da-rede-federal. Acesso em 04 maio 2018.

BRASIL. Instituições da rede. (2016b). Disponível em http://redefederal.mec.gov.br/instituicoes. Acesso em 4 maio 2018.

BRASIL. Instituto Federal de Educação, Ciência e Tecnologia Goiano (IF Goiano). Campus Iporá. Química. Iporá, (2017a). Disponível em https://www.ifgoiano.edu.br/home/index.php/cursos-superiores-ipora/222-quimica.html. Acesso em 14 ago. 2018.

BRASIL. Instituto Federal de Educação, Ciência e Tecnologia Goiano (IF Goiano). Campus Rio Verde. Licenciatura em ciências biológicas. Rio Verde. (2017b). Disponível em https://www.ifgoiano.edu.br/home/index.php/cursos-superiores-rio-verde/251-cienciasbiologicas.html. Acesso em 9 ago. 2018.

BRASIL. Instituto Federal de Educação, Ciência e Tecnologia Goiano (IF Goiano). Campus Urutaí. Matemática. Urutaí. (2017c). Disponível em https://www.ifgoiano.edu.br/home/index.php/cursos-superiores-urutai/286matematica.html. Acesso em 1ำ ago. 2018.

BRASIL. Instituto Federal de Educação, Ciência e Tecnologia Goiano (IF Goiano). Projeto político-pedagógico do curso de licenciatura em química do Campus Urutaí-matutino. Urutaí. (2017d). Disponível em https://www.ifgoiano.edu.br/home/images/URT/ProjetoPedaggico-do-Curso---Matutino.pdf. Acesso em 14 ago. 2018.

BRASIL. Instituto Federal de Educação, Ciência e Tecnologia Goiano (IF Goiano). Campus Ceres. Ciências biológicas. Ceres, (2018a). Disponível em https://www.ifgoiano.edu.br/home/index.php/cursos-superiores-ceres/196-licenciatura-emciencias-biologicas.html. Acesso em 9 ago. 2018. 
BRASIL. Instituto Federal de Educação, Ciência e Tecnologia Goiano (IF Goiano). Campus Ceres. Química. Ceres, (2018b). Disponível em https://www.ifgoiano.edu.br/home/index.php/cursos-superiores-ceres/197-quimica.html. Acesso em 14 ago. 2018.

GIL, Antônio Carlos. Como elaborar projetos de pesquisa. São Paulo: Atlas, 2007. OCDE. Education at a Glance 2017. Disponível em https://www.oecdilibrary.org/education/education-at-a-glance-2017 eag-2017-en. Acesso em 4 maio 2018.

PACHECO, Eliezer. Institutos federais: uma revolução na educação profissional e tecnológica. São Paulo: Moderna, 2011.

PORTO, Gabriella. Navegando e aprendendo. Diferenças entre tecnólogo, bacharelado e licenciatura. Infoescola, 2018. Disponível em https://www.infoescola.com/educacao/diferencas-entre-tecnologo-bacharelado-elicenciatura/. Acesso em 29 maio 2018.

SOUSA, Flávio Eliziario de; FREIESLEBEN; Mariane. A educação como fator de desenvolvimento regional. Rev. FAE, Curitiba, v. 21, n. 2, 2018, p. 163-178.

Thiago Oliveira Piloto é mestre em Desenvolvimento Regional pelo Centro Universitário Alves Farias.

Orcid: https://orcid.org/0000-0001-5059-5530.

Endereço: Rua 88, 310, Setor Sul - 74085-010 - Goiânia - GO - Brasil.

E-mail: thiago.piloto@ifgoiano.edu.br.

Joelma de Moura Ferreira é doutora em Ciência da Computação pela Universidade Federal de Goiás.

Orcid: https://orcid.org/0000-0002-1064-100X.

Endereço: Av. Perimetral Norte, 4129, Vila João Vaz - 74445-190 - Goiânia - GO Brasil.

E-mail: joelma.ferreira@unialfa.com.br.

Luis Antônio Vilalta é doutor em Educação pela Pontifícia Universidade Católica de São Paulo.

Orcid: https://orcid.org/0000-0001-7614-3452.

Endereço: Av. Perimetral Norte, 4129, Vila João Vaz - 74445-190 - Goiânia - GO Brasil.

E-mail: vilalta.educacao@gmail.com.

Recebido em 25 de novembro de 2019.

Aceito em 4 de janeiro de 2020.

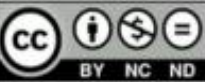

